the sudden rattling of a large window was distinctly heard at about Io p.m., but it was unaccompanied by any sound Judging from the intensity of the disturbances at Torquay and Brighton, I see no reason to doubt the connection of the latter observation with the firing at Cherbourg.

It is interesting to notice how the character of the sound changed with the increasing distance from Cherbourg. At St. Catherine's Point ( 65 miles) and Bonchurch (68 miles), both in the Isle of Wight, the sound was described as exactly like that of heavy guns. At Bournemouth and Muddiford in Hampshire (74 miles) there was a continual rumbling noise, with occasional heavier booms. At greater distances, as far as Lancing, Torquay and Paignton, the prominent reports ceased to be audible, and there was merely a deep monotonous throbbing noise, the pulsations recurring with great rapidity and regularity, resembling a very quick beating of a big drum far away, or the beats of the paddles of a distant and unseen steamer. At very great distances the vibrations (or some of them) do not seem to have attained the requisite strength to be audible to certain observers, one at Lancing (roo miles) referring to a most curious throbbing sensation in the air, and a dull sound like that of a distant train ; while another at Brighton (IO4 miles) remarks that he heard or felt the sound. The rattling of the window and the inaudibility of the vibrations at Menheniot may perhaps be accounted for in this way.

Charles Davison.

\section{SUBJECTS FOR CONSIDERATION BY} ELECTRICAL ENGINEERS.

THE current number (July) of the Journal of the Institution of Electrical Engineers contains a list of subjects suggested by the Council as suitable for papers to be read at the meetings or published in the Joumal. The list is here reprinted, and it should be the means of directing attention to many important problems awaiting solution, as well as eliciting information upon the present position of various branches of electrical engineering.

I. Best methods of generating steam and steam power for variable loads.

2. Comparison of double- and triple-expansion engines for varying load conditions.

3. Automatic handling of fuel in power stations.

4. The present position and applicability of gas or oil engines for electrical power stations.

5. Description of plants for the utilisation of river- or tidalpower in the generation of electrical energy.

6. The present position and prospects of the application of liquid and of powdered fuel in electrical power stations.

7. The utilisation of blast-furnace gases or other waste products of manufactures in the generation of electricity.

8. The application of dust-destructors to the generation of electricity.

9. Electric light and power station chimney shafts ; specialities of their construction and equipment.

Io. Experiences with vibrations from electric light and power stations.

I r. Bearings of shaft and shafting running at high speed.

12. Improvements in dynamos.

13. Comparison of speed and cost of dynamo.

I4. Comparison of single and multiple central stations.

15. The wholesale supply of electricity to towns and factories from centres where very large generating units are employed.

I6. The distribution of electrical energy from a distant generating station through districts served from a different source of supply, or under a separate local authority.

17. Electrical distribution by constant current, direct or alternating.

18. Examination of relative advantages and disadvantages of direct-current and alternate-current transmission.

I9. Examination of relative advantages and disadvantages of two-phase and three-phase transmission.

20. Methods of controlling speed of alternating current motors.

21. Practical methods of measurement in connection with polyphase distribution.

22. Methods for the conversion of direct current into alternate current.

23. Methods of providing for electrical supply during hours of small demand.

24. Utilisation of lighting plant for other work cluring the hours of small demand.

NO. I607, VOL. 62 ]
25. The electrical equipment of large blocks of ottices in a city.

26. Economy of design in the manufacture of small electric fittings.

27. Portable electric lamps of the "safety" type, or otherwise. 28. Enclosed arc lamps.

29. Improvements in incandescence electric lamps.

30. Incandescence electric lamps with filaments other than pure carbon.

3I. Application of electrical transmission in factories :-

(a) Detailed description, giving sizes of motors and power provided.

(b) Comparison of separate or combined direct and alternate-current methods.

(c) Combination of lighting and power for such purposes

32. Electricity meters.

33. Description of electrical methods, or comparison of these with other methods, of propelling vehicles.

34. The supply of electrical energy for tramway purposes.

35. The use of electrical methods of traction on railways served by steam-driven locomotives.

36. The economy and design of electrical elevators.

37. The design and economy of electrically driven pumps.

38. The utilisation of electrical energy in mining.

39. The applications of electrical energy in warfare.

40 The use of electricity in the textile and other industries.

4I. The application of electricity in musical instruments.

42. Electro-therapeutics.

43. The establishment of public time-services by electricity.

44. Recent advances in telegraphy.

45. Applications of alternating currents in telegraphy.

46. The transmitting capacity and load factor of telegraph circuits.

47. Hertzian telegraphy.

48. Methods, in aërial telegraphy, of restricting signals to selected stations

49. Recent improvements in telephony.

50. Descriptions of systems tending to simplify the interchange of telephonic communications.

5r. The talking capacity and load factor of telephone circuits.

52. The application of electricity to the generation of heat for domestic purposes (cooking, ventilation, heating, \&c.)

53. The construction and use of electric furnaces.

54. The application of electricity to the welding or annealing of metals.

55. The application of electrical heating methods in chemical or metallurgical operations.

56. The applications of electricity in metallurgical processes.

57. The applications of electrolysis in the smelting or refining of metals, or in the chemical industries.

58. The electrical equipment of chemical factories.

59. Improvements in primary batteries.

6o. Examination of the present position of secondary batteries in electrical engineering.

6r. The direct generation of electrical energy from fuel.

62. The economic employment of thermo-generators.

63. Improvements in the apparatus for producing, and in the applications of, kathode and Röntgen rays.

64. The relative suitability and efficiency of the different materials available for any of the requirements of electrical engineering.

65. The electric strength of di-electrics.

66. Recent advance in the manufacture or use of insulating materials.

67. New insulating materials.

68. Electrical applications of aluminium, sodium, \&c.

69. The electrical uses of the rarer metals.

70. The treatment, testing, specifications, or uses of iron or steel, or of iron alloys, for magnetic purposes.

7I. The manufacture of permanent magnets.

72. The relation of chemical composition and physical condition to the electrical or magnetic properties of substances, considered in its bearing upon electrical engineering practice.

73. High-resistance metals for instruments or resistance coils.

74. New resistance alloys.

75. The protection of laboratories and observatories against magnetic disturbances due to local causes.

76. Recent legislation in its relation to electrical undertakings.

77. The relations between electric lighting or power corporations and municipal authorities. 